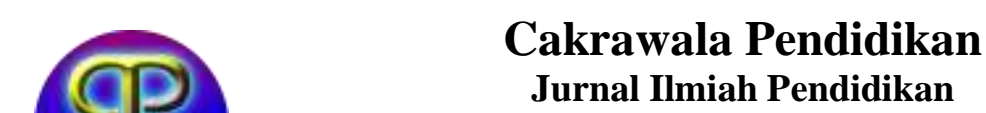

Vol. 41 No. 1, February 2022, pp.154-169

https://journal.uny.ac.id/index.php/cp/issue/view/2208

DOI: https://doi.org/10.21831/cp.v41i1.40687

\title{
Self-Regulated Writing (SRW) strategies during the completion of dissertation: a case study
}

\author{
M. Affandi Arianto ${ }^{1 *}$, Anik Nunuk Wulyani ${ }^{2}$ \\ ${ }^{1}$ Universitas Negeri Padang, ${ }^{2}$ Universitas Negeri Malang \\ *Corresponding Author: affandia@fbs.unp.ac.id
}

\begin{abstract}
Previous studies have highlighted the benefits of self-regulated writing (SRW) strategies in the EFL/ESL context. However, little is known about the use of these strategies in the process of completing a dissertation. Anchored by the limitations of previous studies, this case study aimed to investigate and understand the use of SRW strategies by Indonesian doctoral students majoring in English Language Education. Through purposive sampling, four doctoral students at a public university in Indonesia were selected as the participants. The data were collected through semi-structured interviews. The qualitative data analysis indicated that the participants used eight SRW strategies, namely idea planning, noticing, text processing, selecting physical environments, seeking social assistance, feedback handling, goaloriented monitoring and evaluation, and self-talk. This article provided descriptions and explanations of how each strategy was used in the process of completing the participants' dissertations. The findings of this study also provide pedagogical implications especially in raising doctoral students' awareness in using SRW strategies as well as contributing to the theoretical development of SRW theory.
\end{abstract}

Keywords: dissertation, doctoral student, self-regulated writing strategy

\begin{tabular}{llll}
\hline Article history & & & \\
Received: & Revised: & Accepted: & Published: \\
16 October 2021 & 10 November 2021 & 1 December 2021 & 19 February 2022
\end{tabular}

Citation (APA Style): Arianto, M. A., Wulyani, A. N. (2022). Self-Regulated Writing (SRW) strategies during the completion of dissertation: a case study. Cakrawala Pendidikan: Jurnal Ilmiah Pendidikan, 41(1), 154-169 https://doi.org/10.21831/cp.v41i1.40687

\section{INTRODUCTION}

Doctoral programs play an important role in fostering the development of researchers and preparing them for research-focused careers (Conn, Zerwic, Rawl, Wyman, Larson, Anderson, Fahrenwald, Benefield, Cohen, Smith, Topp, \& Markis, 2014; Jones, 2013). The program is a crucial part in higher education context since it enforces a generation of intellectuals who are able to create and contribute their knowledge to society. In the journey of obtaining their degree, doctoral students have to complete their dissertations. However, this is the most daunting part of the doctoral program (Shahsavar \& Kourepaz, 2020). The process requires some efforts to be more than just persistent, for example, keeping up their discipline, initiative, motivation, critical thinking, and consistency. To be more precise, the doctoral student has to take responsibility to determine his/her research topic, holding it in the supervision process, and maintaining the quality of the final product.

Mostly found in the Indonesian context, doctoral students who propose a topic in their first semester at the university under studystart writing their dissertations when they enroll in the dissertation proposal development (DPD) course in the second semester. These factors may lead into a certain condition, such as stress, lack of motivation, and unwillingness to write, that eventually hinder their productivity to write the dissertation (Russell-Pinson \& Harris, 2019). The feeling of isolation, lack funding, doubts about abilities or strengths, and time management may also become major factors affecting students' dissertation completion(Castello, Pardo, SalaBubare, \& Sune-Soler, 2017; Cornwall, Mayland, Meer, Spronken-Smith, Tustin, \& Blyth, 2018; Fernandez, Sturts, Duffy, Larson, Gray, \& Powell, 2019; Lech, Nieuwerburgh, \& Jalloul, 2017). 
Moreover, especially for non-native English speakers, the language barrier is frequenly found when they are writing in English (Hajar, 2016; Huerta, Goodson, Beigi, \& Chlup, 2016; Yonezawa, 2015). The appropriate use of strategies, however, can go a way too far to ameliorate these problems.

Self-regulated writing (SRW) strategies have been receiving scholarly attention. In an educational context, it can be defined as the process done by students by incorporating their metacognition, affect, and social dimensions (Teng, 2019). Self-regulated students are those who are metacognitively aware of every process of learning something (Lukes, Jones, \& McConnell, 2021; Widharyanto \& Binawan, 2020). In the context of higher education, the strategies can allow doctoral students to be more familiar with how to use their cognition, plan their goals, control their emotions, set their environment, and control their motivation in the process of dissertation completion (Abadikhah, Aliyan, \& Talebi, 2018; Umamah \& Cahyono, 2020). Understanding the use of SRW strategies can assist doctoral students who are in the process of completing their final dissertations in arranging their plans, setting and monitoring targets, organizing emotion, managing the thinking process, and creating environments.

Due to the importance of SRW strategies, some empirical studies have been conducted to examine the use of the strategies for the completion of tasks (e.g., Abadikhah et al., 2018; Teng \& Zhang, 2016; Umamah \& Cahyono, 2020). Teng and Zhang (2016) found that the students generally used several SRW strategies to complete their L2 writing tasks, such as idea planning, peer learning, goal-oriented monitoring and evaluating, feedback handling, and self-talk. Abadikhah et al. (2018) revealed that six dimensions of SRW strategies, namely motive, method, time, physical environment, social environment, and performance were differently used by the students at different proficiency levels. To support this idea, in a recent study, Umamah and Cahyono (2020) also found that students used academic or journal articles as sources to gain their ideas, and in completing their writings, they used other strategies, namely asking for proofreading and revising works.

Despite the increasing number of studies of doctoral students (Davis, Wladkowski, \& Mirick, 2017; Fernandez et al., 2019; Yang and Bai, 2019), there has been virtually no qualitative study evidence exploring Indonesian doctoral students' SRW strategies. Besides, studies focusing on ELE doctoral students have also received little attention so far (Rahimi, Yousoffi, \& Moradkhani, 2018). One exception is Yang and Bai (2019) who explored the strategies used by Chinese doctoral students in Australian universities. The critical question is whether the strategies used by doctoral students in the field of education differ from those in the fields of economics, marketing, and management. Moreover, they limited their focus only on the participants' metacognitive strategies, including planning, self-monitoring, and self-reflecting. Zimmerman (2013) in his social cognitive perspective claims that SRW strategies involve not only metacognitive aspects but also behavioral and motivational aspects. Thus, future studies should focus on a specific field in the doctoral program using qualitative research methods that can uncover how the students use the types of SRW strategy, as well.

The paucity of qualitative evidence from previous studies calls for a detailed investigation of how doctoral students use their SRW strategies. Therefore, this study aimed to investigate the SRW strategies used by Indonesian ELE doctoral students in the process of completing their dissertations.

\section{METHOD}

The design used in this study was a case study. This method draw the data qualitatively by occupying a form of interviews as its tool. Considering the benefit gained from this qualitative method, finally, this study aimed to provide a rich description and explanation of the ELE doctoral students' SRW strategies in the process of their dissertation completion. This study was undertaken at a large public university in Malang, Indonesia. This university offers a doctoral program in ELE. To maintain the quality of learning and supervision, this university limits the admission of ELE doctoral students to ten students only in each academic year. This regulation has been set for several years before this study was conducted with the aims of shaping the 
graduate students into researchers and preparing them for research-focused careers that can build, sustain, and nourish the quality of teaching English. In this program, the doctoral candidates complete their study within three years (43 credits), including writing and defending their dissertations. In the first semester of their doctoral program, they enroll in the exploratory research course that deals with a critical review of research in ELE. The course may become the foundation of their dissertation development in the second semester and in the later stages of the process of finishing up their dissertations. Once they have completed their first semester courses and got their supervisors at the beginning of the second semester, they can begin writing their dissertations.

To recruit the participants, the researchers employed the purposive sampling technique (Friedman, 2012). Four participants were recruited. The selection criteria were that they were in the process of completing their dissertations, and they had a willingness to participate without hesitation marked by filling consent forms. Besides, they were from different cities and had never studied in the city of Malang prior to their doctoral studies. After six months of observation, they allowed the researchers to deeply explore their real-life experiences during the completion of their dissertations. To ensure anonymity, the participants' names were made pseudonyms, and any identifiable information was kept confidential. The participants' demographic information including the state of their dissertation progress is portrayed in Table 1.

Table 1. Participants' Demographic Information

\begin{tabular}{|c|c|c|c|c|}
\hline \multirow[t]{2}{*}{ Aspects } & \multicolumn{4}{|c|}{ Participants } \\
\hline & Roy & Sari & Yudi & Mita \\
\hline Gender & Male & Female & Male & Female \\
\hline Age range & $25-30$ & $50-55$ & $30-35$ & $35-40$ \\
\hline Receiving & Yes & No & Yes & Yes \\
\hline \multicolumn{5}{|l|}{ Scholarship } \\
\hline State of Research & - Finishing up & - Writing & - Writing & Writing \\
\hline Activities & - Preparing & research & research & research \\
\hline & for & reports and & reports and & report \\
\hline & dissertation & discussion & discussion & \\
\hline & examination & - Finishing up & - Finishing up & \\
\hline
\end{tabular}

To obtain an in-depth understanding, we conducted semi-structured interviews. In this context, the interviews were effectively helpful to understand the doctoral students' experiences and also provided a useful description of the collected data (Wang \& $\mathrm{Li}, 2014$ ). The questions were developed based on how the students processed their strategies, evaluated and improved their strategies, and increased motivation (Jackson \& Park, 2020). The guidelines had been piloted to other doctoral students and revised based on the feedback received from two experts. Some probing questions were also asked to obtain clarifications and elicit the participants' thoughts.

The interviews were done by using the participants' national language (Hu \& Gao, 2017). It aimed to help them express their feelings deeply. The interviews were recorded and the recorded data were then transcribed. The data were translated into English and checked by a professional translator. Qualitative data analysis (Chamberlain, 2006) was conducted in this study. We identified the relationship of each piece of data via inductive and deductive thinking in the process of data analysis. We coded, categorized, and conceptualized the data. We performed detailed reading to identify the SRW strategies. The strategies found were grouped according to the SRW strategies adapted from Teng and Zhang (2016) by considering the insights of $\mathrm{Hu}$ and Gao (2017), and Zimmerman (2013) (Figure 1). The classification of SRW strategies was discussed with two experts and claimed to be reliable so that it could be used as the analysis guidelines. Moreover, we also invited a scholar who understands the concept of SRW strategies to check the data. We periodically checked the consistency of the results of the data analysis. To establish the credibility of the data, we conducted member checking to ensure the accuracy of the data in which the 
participants were provided with the results of data interpretation to be verified and clarified based on what they had experienced.

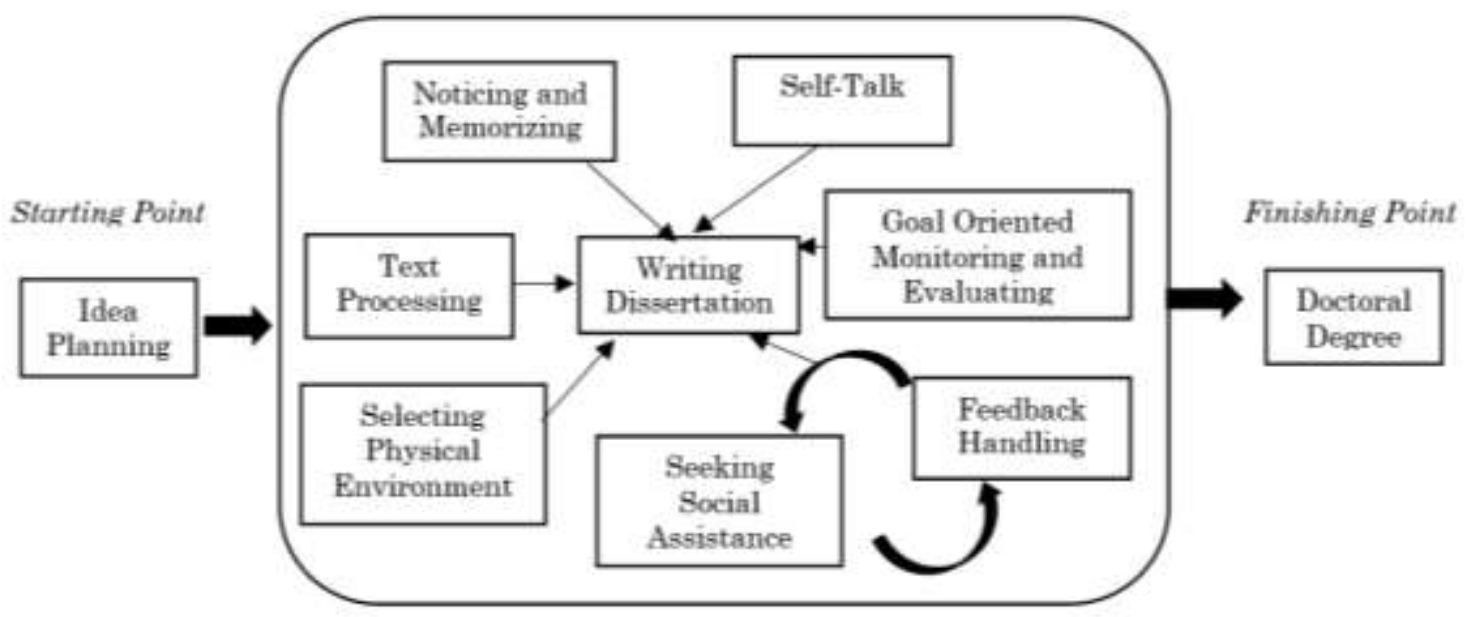

Figure 1. SRW strategies (Adapted from Hu \& Gao, 2017; Teng \& Zhang, 2016; Zimmerman, 2013)

\section{FINDING AND DISCUSSION \\ Finding}

Based on data analysis, eight SRW strategies were found in this study, namely idea planning, noticing, text processing, selecting physical environments, seeking social assistance, feedback handling, goal-oriented monitoring and evaluating, and self-talk. The explanations and exemplifications of each SRW strategy obtained from data analysis can be seen in the following points.

\section{Idea Planning}

Idea planning refers to the initial activities indicating students' goal setting, such as organizing agenda, establishing research priorities, and preparing things that contribute to the process of finishing up their dissertations (Yang \& Bai, 2019; Zimmerman, 2013). Every participant reported that they had set their plans while working on their dissertations. One of them had prepared his dissertation topic before he registered as a doctoral student, as demonstrated by the following excerpt.

\section{Excerpt \#1}

"In my opinion, a doctoral study is not easy to be completed. However, I am a disciplined person. I set my plans before I continue my study. I decided on the topic when I was an active lecturer in my institution."

(Roy)

In the first semester, the participants had enough time to review previous studies, establish research priorities, and provide rationales that the chosen topics would contribute to the advancement of knowledge. Doctoral students at the university took the Exploratory Research for Publication (ERP) course in the first semester. This course aims to assist the students in building their ideas and prioritizing research needs for research article publication. However, the lecturer of the course also has a plan to encourage the students' topics in the course to become their dissertation topics in the next semester in the Dissertation Proposal Development (DPD) course. When semester two came, Roy proposed the topic that had been prepared and suggested by his ERP lecturer to the DPD course lecturer. After it had been accepted by his lecturer in the DPD course, he proposed his dissertation topic to the convener of the ELE doctoral study program, and the topic was accepted. The convener also assigned his supervisors at that time. In the DPD course, he developed the topic into his dissertation. During the course, the DPD lecturer also discussed with the participants' supervisors concerning the progress of the participants' dissertations. 
On the other hand, the other participants decided on their dissertation subjects during the DPD course, thus they did not bring their ERP topics with them. Mita, the representative of the other three participants, prepared her new dissertation topic based on her evaluation in the firstsemester course. She changed her topic because it was not approved by the DPD lecturer to be a good topic for her dissertation. However, she did not give up to propose another topic for their dissertation. By looking for possible and up-to-date topics from journal publications, her new topic was accepted to be developed into the dissertation. She summarized the previous studies that had been read. She organized the summary results into a table that had been created. From the activity, she could identify research gaps. The research gaps then inspired her to create a new topic for her dissertation.

\section{Excerpt \#2}

"I was really frustrated because my first topic was not approved to be my dissertation topic. What I had planned and expected was different. My first topic was declined by the DPD lecturer. For the new topic, I collected and read several articles. I spent my time reading the articles in three weeks. Each article that has been read was summarized and tabulated into a table in my Microsoft word. It eased me to identify the research gaps. I proposed the topic based on the gaps. My new topic was accepted to be my dissertation topic by my DPD lecturer and the convener of the ELE study program, and I got supervisors for my dissertation."

(Mita)

The idea planning strategy was not only used to prepare dissertation topics. All of the participants had planned out their writing timetables for each portion of their dissertations. Their supervisors requested them to create a schedule for completing their dissertation. They showed and discussed the timeline when they met their supervisors. Besides, in terms of establishing arguments in their dissertation sections, the participants' supervisors also suggested that they made a target of reading articles from reputable journals (i.e., one article in a day). They said that strong arguments would be established by reading many related articles from journals.

Therefore, it is indicated that the participants' lecturer and supervisors seriously set up their perspectives concerning the process of dissertation writing. They agreed to ask the participants to create target achievements for their dissertation completion. The participants also followed the ways, especially of reading sources and making a timeline in writing every section of the dissertation. It could be expected that they could complete their dissertations on schedule if they relied on what had been planned.

\section{Noticing}

Noticing can be done in several activities, such as highlighting the important information from sources (e.g., articles, books, dissertations, etc.) that have been read. It can be in the form of identifying useful explanations and writing them down in notebooks to memorize (Hu \& Gao, 2017; Teng \& Zhang, 2016). This study also found that the participants used the strategy in the DPD class and the process of supervision.

Excerpt \#3

"When I wrote the introduction and discussion sections, my supervisors asked me to review previous research findings. I noticed, highlighted, and wrote the steps that were explained by them in my notes. I marked the important pages using my sticky notes to make me remember."

(Sari)

Some participants used another way to remember important information. Roy, for instance, used his phone to capture the slides of his lecturer's and peers' presentations during the lecture. $\mathrm{He}$ also used the phone to record his supervisors' explanations during the process of supervision. Moreover, the participants also used the strategy of noticing outside the class. For instance, Mita was instructed to go to the library to check and highlight the components of dissertation sections written by her predecessors who had graduated from the institution. 


\section{Excerpt \#4}

"My supervisor asked me to go to the library to read the previous dissertations written by those who had graduated. As I said before, I identified the important points related to the literature review, methodology, and discussion sections and put them into my Microsoft word. Those were organized well in the form of tables. The activity helped me a lot, especially in organizing my dissertation sections."

It can be seen that the participants' ways to notice and memorize the important information were by writing down their lecturer's presentations in their notebooks, using sticky notes to make them remember the information, and recording their lecturer's and supervisors' explanations.

\section{Text Processing}

Text processing strategy can be in the form of maintaining the cohesiveness or connection among sentences. Students can also check whether the content of their writings has been clearly expressed (Teng \& Zhang, 2016). In this study, it was also found that the participants used this text processing strategy while they worked on their dissertations. Sari, one of the participants, knew well the way to construct an introduction and discussion sections after she had joined an online workshop. The speaker of the workshop gave several steps to develop the sections. She got the speaker's PowerPoint presentation that can be learned anytime. She also told us that she got the largest collection of academic phrases that can be considered while writing her dissertation (i.e., Academic Phrasebank).

\section{Excerpt \#5}

"I joined several workshops in the pandemic situation. I attended a workshop related to academic writing. The speaker shared the Academic Phrasebank in the form of e-books. I learned how to justify the research, review previous studies, propose novelty, report results, discuss findings, and some others related to writing each section of a dissertation."

(Sari)

Besides, one participant (Roy) needed to get his dissertation proofread before he met his supervisors. He was not confident enough in terms of the English language that he put on his writing. He had a small group, and the members of the group helped each other, particularly to proofread their friends' dissertations. In addition, the four doctoral students agreed that the Grammarly software was useful to help them check their language use. Although they were ELE students, they still needed to consider their English language use in academic writing. It is seen in the excerpt from the interviews with Yudi.

\section{Excerpt \#6}

"Grammarly is good software. It can identify typos. I used it during the process of writing my dissertation, or after I had finished writing every section of my dissertation. We can also learn the common English phrases because it provides the corrected phrases too."

(Yudi)

Paying attention to the organization of ideas from some sources such as articles, books, and dissertations could also help them work on their dissertations. It is seen in the following excerpt from the interviews.

\section{Excerpt \#7}

"I made my screen separated into two parts. The left side was the articles from reputable journals and the right side was my Microsoft word. For example, when I got difficulties in comparing and contrasting previous studies in the introduction and discussion sections. I looked at the left side and identified how the authors wrote them in their articles." 
The findings of this study indicate that the participants did some activities in using a textprocessing strategy. One participant relied on the roles of Academic Phrasebank to increase the quality of their dissertations in terms of establishing the importance of the topic, presenting research gaps, reviewing previous studies, and reporting and discussing findings. Besides, all of them agreed about the usefulness of Grammarly to check their language use. Also, understanding the rhetorical structures of dissertation sections is of utmost importance for doctoral students to make their ideas flow in sequential order and avoid errors in reasoning that undermine the logic of arguments.

\section{Selecting Physical Environments}

In SRW strategies, the two best-known models proposed by Winne and Hadwin (1998) and Zimmerman (2000) consider environment structuring to be one of the strategies in which students monitor and manage their external resources. Abadikhah et al. (2018) also consider the physical environment as a dimension that support the students in completing their tasks. In this study, all the participants agreed that quiet places could be the best environmental resources for them to enhance their concentration. It is displayed in the excerpt from the interviews below.

Excerpt \#8

"My best place is the library, studying rooms, or doctoral cubicles. I can't stand crowded places. My dissertation writing was more effective and efficient when I was in the library because I could check and learn how to write the research reports from the library too."

(Roy)

From the excerpt above, it is indicated that quiet and steady environment may lead into the effectiveness of participants' concentration during the process of finishing up their dissertations. Their focus elevated, and it could enhance their productivity during the writing process. Reading and reviewing previous studies become difficult activities for doctoral students unless their environments make them enjoy doing the activities. It also indicated that the participants were more focused on working on their dissertations in quiet places or private rooms.

\section{Seeking Social Assistance}

Seeking social assistance is a way wherein students attempt to control their behavior (Anthony, Clayton, \& Zusho, 2013). When students encounter multi-faceted complexities while working on writing tasks, they need help and they may seek social assistance from peers, teachers, experts, etc. (Teng \& Zhang, 2016; Zimmerman, 2013). In this study, the participants used to seek social assistance from a WhatsApp group. They shared ideas, asked for clarifications, supported each other, and helped others in the group. It can be seen in the following excerpt from the interviews.

Excerpt \#9

"Our class has a WhatsApp group. We discussed how to establish a good supervision process with the supervisors. We also shared important information, such as joining online workshops about collecting and analyzing data in quantitative and qualitative research."

(Yudi)

Besides, another participant, who was analyzing and interpreting the data, knew how to conduct statistical analysis after being assisted by his friend.

Excerpt \#10

"I was not good using SPSS. When I was asked to analyze my data using Manova, I got confused. Lucky me, I have a friend who knows more about statistics. He gave me explanations in detail. Now I understand how to analyze my data and interpret the results of the data analysis using the software." 
Moreover, social assistance was not only from their friends in the class, but they might also have other social resources such as, their colleagues in the office, or even their broader academic communities. In this study, Sari was a member of a small community. She met the members of her community regularly once a week via Zoom. In the meetings, she received some suggestions and solutions concerning the progress of her dissertation.

\section{Feedback Handling}

A doctoral student tends to be more aware of handling the advice he/she receives (Yang \& Bai, 2019), even the feedback comes from his/her peers or supervisors (Teng \& Zhang, 2016). This strategy is also closely related to the social assistance strategy that assists students during working on their dissertations. In this study, the participants decided to follow the inputs from their peers and supervisors after the feedback and comments had been evaluated.

Excerpt \#11

"In writing the method section, my friends suggested elaborating the arguments on how I selected the participants. However, I thought what had been written in my dissertation was good. Well. I respected the suggestion given, but the final decision was on me."

(Sari)

\section{Excerpt \#12}

"I got several written feedback, particularly in the method and discussion sections. When I read their suggestions, I got confused. I met him in the office, and we had a tight discussion related to the suggestions given. My supervisors had told me that they always have time from Monday to Friday to discuss my dissertation. In this pandemic, I discussed my dissertation with them via WhatsApp, and I sent my draft via Email."

(Yudi)

As shown in excerpts 11 and 12, it indicated that the feedback handling strategy was used by the participants when they received inputs from external resources, such as friends and supervisors. Sari and Yudi did not directly accept all suggestions given to them. They tended to evaluate the social assistance they had received. If suggestions, opinions, and feedback make sense, they will follow the assistance

\section{Goal-Oriented Monitoring and Evaluation}

Goal-oriented monitoring and evaluation can control what students do, such as making sure whether goals can be successfully achieved and monitoring whether every step that they take is on the right track (Teng \& Zhang, 2016). In this study, Roy evaluated what his lecturer had said and considered the instructions to follow. It is depicted in excerpt 13.

Excerpt \#13

"My supervisors asked me to read many articles. However, it was not working for me. I explained to them that the more I read the more I was confused. Then, they highlighted and recommended the articles that were closely linked to my literature review, method, and discussion sections. I set my plan to read them, one article in a day. I could establish my arguments and justify my research in the introduction, literature review, and discussion sections. I knew how to write the procedures of collecting and analyzing data, as well."

(Roy)

Besides, the participants were guided by their supervisors to control and monitored their reading sources and considered the publication date. They only focused on up-to-date topics. Trend issues are the issues published five years back. They can be claimed to be up-to-date issues that can still be discussed and studied. 
Moreover, one of the participants also needed to change her strategies due to the pandemic situation (i.e., Covid-19). Mita realized that she needed to change her ways of reading articles to enhance the quality of her dissertation.

Excerpt \#14

S: "Three months ago, I only have one day to read articles and focus on my dissertation writing. I think the other parents may feel the same in this Covid-19 outbreak. Online schooling is like 24 hours. I have to monitor my children when they are studying using online modes."

I: "You need to have time for your dissertation writing, such as an hour a day for reading and writing your dissertation."

S: "Yes, I have been implementing it since two weeks ago. I realize that I should go back to my track. Finishing my dissertation."

(Mita)

Mita was a mother who also had to monitor her children during online learning. We can infer that she realized and evaluated her time management. She used to have sufficient time to read articles, but in the pandemic situation, her time was fully devoted to controlling her children's online schooling, so that she only had very limited time to focus on her dissertation.

Another participant also faced a challenge in the process of collecting data through observation due to the Covid-19. However, she successfully evaluated and found other ways to reach her goal. Sari shared:

Excerpt \#15

"My research is about interaction in classrooms. In January, I had a fixed plan. However, due to the Covid-19 outbreak, every school shifted to an online class. No physical interaction. Oh my God. I needed to evaluate what I had set. I contacted the teachers, and I was invited to their online class, zoom, google meet, and WhatsApp groups. I observed how student-teacher and student-student interactions in the applications. For the next time, I have to make a plan B for every plan that I have made."

(Sari)

From Excerpt 15, we can see how Sari anticipated the condition (i.e., Covid-19 outbreak) while she had to collect the data. She was not out of ideas. Although she was not young anymore, she tried to adjust herself to technology. As a result, she obtained the data. Based on the interview, it indicated that she learned something from the situation. She would prepare the alternatives to every plan that would be made.

\section{Self-Talk}

According to Anthony et al. (2013), self-talk is a motivation area that functions to receive positive inputs and avoid negative thinking that can make students unmotivated to do things. Selftalk can be like reminding, persuading, and telling ourselves to practice more or pushing ourselves to work hard and keep on writing (Teng \& Zhang, 2016). In the process of completing a dissertation, someone needs to adjust their capacity and motivation level by themselves. The interviews indicated that the participants set their strategies to motivate themselves when they were down.

Excerpt \#16

"I had been in a situation where I did not do anything in several weeks. I did not revise my dissertation. I did not know why. I became a lazy person. Until I knew that my friend got a financial problem. From that time, I remembered how I got the scholarship. I should be grateful that I got a scholarship. I have to finish my dissertation. Now, I am on my track. I follow my timeline again. What I want to say is that we have to consider time management." 


\section{Excerpt \#17}

"When the semester end, I have to pay for my tuition fee and my children's school fees, as well. I did not get a scholarship. When I was down or frustrated during my working on my dissertation, I told to myself. If I did not graduate soon, I will suffer a loss. I have spent a lot of money on my study. So, I need to set a target to get my dissertation done this year. I always put a statement in my mind. Don't waste your time."

In this study, it was found that the participants used their ways of using positive self-talk, such as ensuring and reminding themselves. Some participants got scholarships from the Indonesian government. They were required to complete their doctoral program within three to four years. What Yudi did to increase his motivation was that he talked to himself and remembered his struggles to get the scholarship. Also, Sari always thought positively, and he promised himself to achieve the degree as soon as possible.

Moreover, the doctoral students used the idea planning strategy in proposing dissertation topics and making a timeline for their dissertation completion. They also set a goal of reading more than one article a day. It gave them important knowledge to strengthen the arguments in their dissertations. In terms of using the noticing and memorizing strategy, all the participants agreed that their lecturer's explanations in the DPD class were important to be noted. They also turned on their recording tools while they were discussing with their supervisors during the supervision. Furthermore, the participants applied the text processing strategy in the process of finishing up their dissertations, such as using software to check their grammar after they had finished working on each section of their dissertations. They also learned the rhetorical organization of every dissertation section from different sources so that they could increase the quality of their dissertations. The participants did not hesitate to ask for proofreading and seek social assistance when they were stuck in dealing with several parts of their dissertations since they had small groups and communities.

To sum up, all the participants agreed that their environments influenced their dissertation productivity. They preferred to write in relaxing environments such as libraries, hubs, or other quiet areas. They believed that such places could increase their concentration when working on their dissertations. The participants also evaluated every situation that happened during working on their dissertations. They had made alternative plans in case they faced an unexpected situation. In a similar vein, they also evaluated the feedback given by their external resources (i.e., supervisors, lecturers, peers, and communities) although mostly the feedback given by their supervisors was considered more in the process of revising their dissertations. Last, positive selftalk could be the best way to boost their motivation to finish their dissertations. As seen in figure 2 below. 


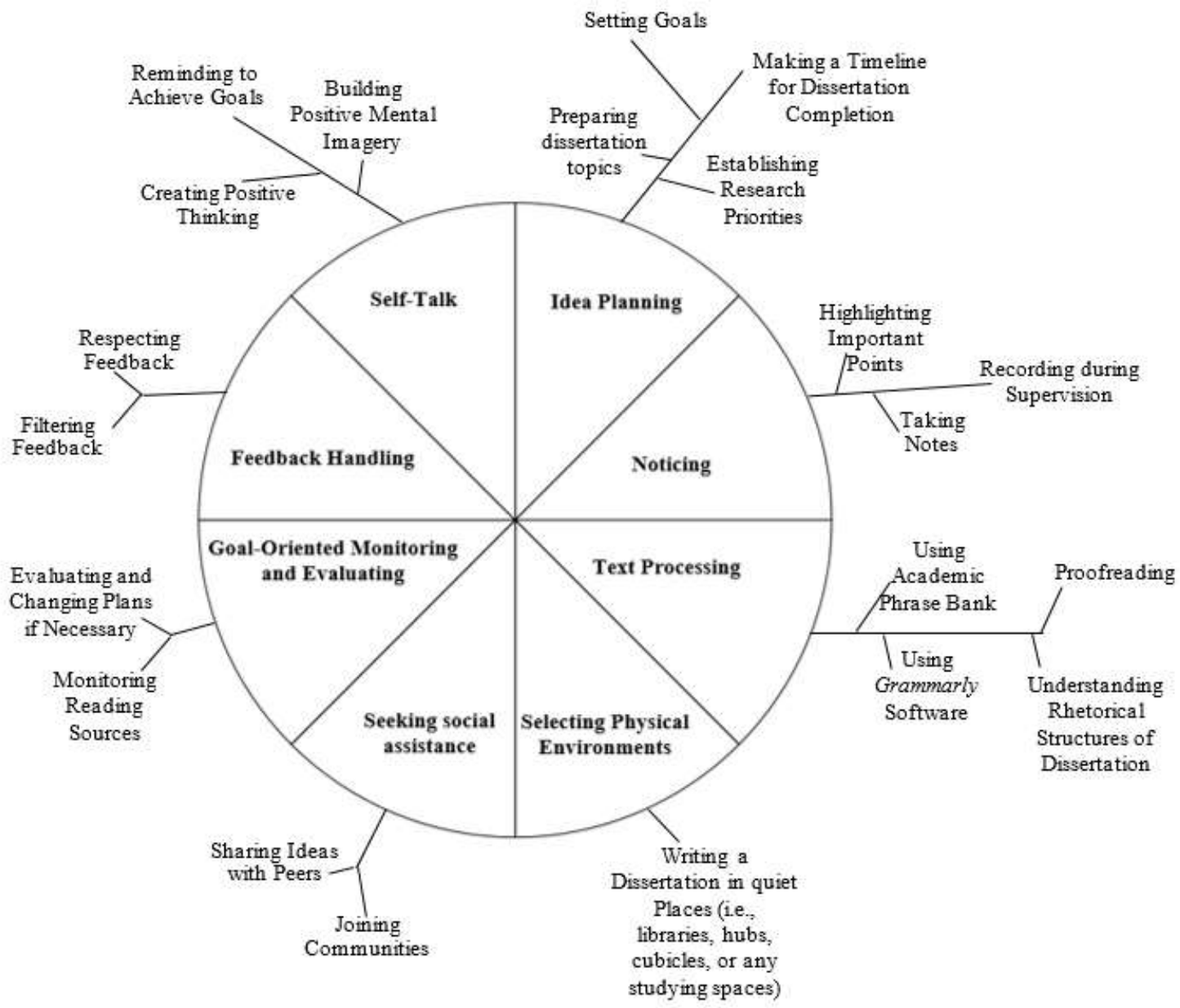
Figure 2. The ELE Students' SRW Strategies Found in the Process of Dissertation
Completion

\section{Discussion}

This study has painted a detailed picture of eight SRW strategies used by the four ELE doctoral students in the process of completing their dissertation. The idea planning strategy serves as an initial strategy used by ELE doctoral students in which they prepared and propose topics, set their goals, and make a timeline for the completion of their dissertations. This finding confirms that of Yang and Bai (2019) who found that Chinese doctoral students in Australia also tended to be well-prepared, especially in establishing research priorities in planning. This is also in line with Lei (2016), who claims that students need to set the time of task completion to keep them on track and achieve what they have planned. Moreover, it also echoes a previous investigation done by Devos, Linden, Boudrenghien, Azziz, Frenay, Galand, and Klein (2015) who found that the completers in the doctoral program in Belgium always set their own planning to reach their goals. Setting doctoral students' planning and being responsible with it give a positive correlation to the completion of their doctoral program, particularly in the completion of their dissertations (Shin et al., 2018).

In the noticing strategy, this study found that the participants enacted salient ways of internalizing information. The finding of this study conforms to what has been found by $\mathrm{Hu}$ and Gao (2017) that self-regulated students used the strategy of noticing when they identified and highlighted important and useful information that could contribute to their task completion. Also, the participants in this study used their phones to record what their supervisors were explaining and then relistened outside the class to help them internalize the information. Similarly, Hajar (2016) suggests that doctoral students need to record every supervisors' suggestion or feedback 
because it helps them to notice the important information for their dissertation revisions. Thus, doctoral students need to anticipate missing information by taking notes and utilizing some features of technology, such as audio and video recording to document important information obtained from external resources, such as lecturers, supervisors, communities, and peers.

Text processing strategy was used by the participants during working on their dissertations. In the EFL context, students need to check their use of language, grammatical mistakes, spelling, and punctuation (Teng \& Zhang, 2016). Some EFL students may be less concerned with their language use, particularly in written communication. (Umamah \& Cahyono, 2020). However, dealing with English academic writing, especially a dissertation, Paltridge (2004) suggests that students focus on their grammaticality, organization, and arguments. Grammarly is claimed to be a breakthrough for assisting ESL/EFL students because it provides more grammatical feedback and reduces errors in terms of diction, grammar, punctuation, and spelling in their writing (Ranalli, 2018). In line with Teng (2019) who found that learning and understanding Englishlanguage academic writing is essential in China. Thus, it is also suggested that EFL countries provide a compulsory course of English-language academic writing to increase the quality of students' academic writing skills, especially in writing a dissertation for doctoral students.

In selecting physical environments strategy, the finding of this study advocates the theory of Zimmerman (2013) who claims that students involve their dynamic activities within the physical environment. Students need to isolate themselves from unnecessary noisy places so that they can be more focused to read, think, and write (Abadikhah et al., 2018). In the context of higher education, physical resources, such as libraries, hubs, cubicles, or labs, are important determinants contributing to dissertation productivity. This also happens in universities in the Netherlands in which the doctoral students are given studying spaces or rooms to explore their thought, ideas, and opinions during working on their dissertations (Rooij, Fokkens-Bruinsma, \& Jansen, 2019). Reading and reviewing previous studies also become difficult activities for doctoral students (Yang \& Bai, 2019) unless their environments make them enjoy doing the activities.

Moreover, in our study, the Indonesian ELE doctoral students found the enjoyment of using their WhatsApp group to interact with their peers, ask for information and clarification, and share ideas. Besides, one of the participants had another community outside the class. She regularly met and joined the community via Zoom once a week. It indicates that joining communities and having discussions in small groups can be the best ways to share ideas. This study confirms the finding of Mullen (2005) who found that doctoral students naturally will experience a union with others. They can build communities especially for getting feedback and doing self-reflection (Aghaee \& Hansson, 2013). The finding of our study is also in line with Holmes, Robinson, and Seay (2010), who believe that the African American doctorate candidates specializing in administration education experienced the success of finishing their dissertations on schedule by maintaining relationships with others and maintaining regular communication with their supervisors. Besides, lecturers, peers, or others served as good resources for Chinese doctoral students majoring in education in Australian universities, especially in terms of asking for help (Yang \& Bai, 2019). Therefore, for doctoral students, building a community is needed because it can reduce struggles in the process of completing their dissertations (Russel-Pinson \& Harris, 2019).

In this study, the feedback handling strategy was used by the participants when they received inputs from external resources, such as friends, lecturers, and supervisors. This is in line with $\mathrm{Hu}$ and $\mathrm{Gao}$ (2017), who claim that if suggestions, opinions, and feedback make sense, selfregulated students will follow the assistance. This finding also conforms to Yang and Bai (2019) that Chinese doctoral students in Australian universities respected and followed their supervisors' suggestions, and they opted for better suggestions derived from their peers. Self-regulated students can understand their capacity, and they know how to use their social resources, such as lecturers, supervisors, friends, colleagues, and communities to evaluate, and receive the inputs for their writing quality (Abadikhah et al., 2018).

In goal-oriented monitoring and evaluating strategy, the participants controlled and managed their progress of completing tasks and they adjust the inappropriate strategies in their 
circumstances. This study is also in line with the study conducted by Yang and Bai (2019) that students can do self-monitoring to see whether their study is effective/efficient and if they encounter an unexpected situation, they may reflect and evaluate their actions in their future. Moreover, we can infer that the participants in this study realized and evaluated their time management. One of the participants used to have sufficient time to read literature reviews, but in the pandemic situation, her time was fully devoted to controlling her children's online schooling so that she only had a day to focus on her dissertation. It indicates that the stressors are not only about behavioral issues and physical symptoms (Russel-Pinson and Harris, 2019). The conditions that doctoral students' children shifted from offline to online schooling and that they get involved in their children's activities during the learning process can also influence the participant's mental condition. It is suggested that doctoral students reschedule their agenda, especially managing time concerning the completion of their dissertations.

Students need to increase their motivation by reminding, telling, and persuading themselves to achieve their goals. In this study, it was found that the participants used their ways of using self-talk strategy, such as ensuring and reminding themselves. This study is in line with Zimmerman (2013) who claims that reminding, telling, and persuading themselves to achieve their goals, building positive mental imagery, and creating positive thinking can overcome anxiety and boost motivation. Besides, the finding showed that the participants were ensured to finish their dissertations by telling themselves not to waste the time. They recalled their memories of the struggles to get the scholarships so that they encouraged themselves to keep writing and challenged themselves to finish their dissertations. Excessive stress can disturb students' productivity and motivation (Russel-Pinson \& Harris, 2019), but for doctoral students, it can be managed by thinking positively.

\section{CONCLUSION}

This study has investigated the use of eight SRW strategies (i.e., idea planning, noticing, text processing, selecting physical environments, seeking social assistance, feedback handling, goal-oriented monitoring and evaluating, and self-talk) by Indonesian doctoral students in the process of completing their dissertations. Concerning those mentioned areas, this study is a case study in nature and we do not claim that the findings of this study are generalizable to all ELE doctoral students. This study gives new insights that writing has a relationship with students' SRW strategies. Supervisors should emphasize activating doctoral students' SRW strategies in the process of completing their dissertations. Doctoral students should also understand that time management and regular writing are necessary for the successful completion of their dissertations. They need to prepare their dissertation topics earlier, especially when they have decided to continue their study in the doctoral program.

Moreover, they need to set their plan and schedule their agenda, especially in terms of proposing their topics, developing their dissertations, preparing for the instruments to collect and analyze the data, and writing their research reports. Reading articles from reputable journals can be a catalyst to help doctoral students establish their arguments in their dissertations. Doctoral students need to prepare alternative plans if what they have set is no longer appropriate for certain conditions. Besides, joining small communities or groups can maintain students' productivity and reduce struggles during working on their dissertations. Therefore, this study suggests that doctoral students be involved in small groups in which the members are dissertation writers. The last, doctoral students, as individuals, should have a responsibility to control their stress and emotion during working on their dissertations. Unexpected situations may come during the process (i.e., family conflicts, financial difficulties, challenges dealing with supervisors, etc.), but they have to have positive self-talk to manage their stress.

It should be noted that this study also has some limitations. Since this study was limited to one certain field (ELE) at one university in Indonesia, thus, we encourage future researchers to enact a further study by involving some students from different fields and universities so that wider descriptions of how doctoral students use and perceive their SRW strategies, especially in the process of completing their dissertations can be portrayed. Besides, future researchers can 
usefully explore the SRW strategies used by different levels of students (e.g., those who are writing undergraduate theses, master theses, and dissertation theses). The application of SRW strategies across students' enrollment status (e.g., full-time and part-time students) is also meaningful and suggested to be investigated.

\section{REFERENCES}

Abadikhah, S., Aliyan, Z., \& Talebi, S. H. (2018). EFL students' attitudes towards self-regulated learning strategies in academic writing. Issues in Educational Research, 28(1), 1-17. http://www.iier.org.au/iier28/abadikhah.pdf

Aghaee, N., \& Hansson, H. (2013). Peer Portal: Quality enhancement in thesis writing using selfmanaged peer review on a mass scale. International Review of Research in Open and Distance Learning, 14(1), 186- 203. https://doi.org/10.19173/irrodl.v14i1.1394

Anthony, J, S., Clayton, K, E., \& Zusho, A. (2013). An investigation of students' self-regulated learning strategies: Students' qualitative and quantitative accounts of their learning strategies. Journal of Cognitive Education and Psychology, 12(3), 359-373. https://doi.org/10.1891/1945-8959.12.3.359

Castello, M., Pardo, M., Sala-Bubare, A., \& Sune-Soler, N. (2017). Why do students consider dropping out of doctoral degrees? Institutional and personal factors. Higher Education, 74, 1053-1068. https://doi.org/10.1007/s10734-016-0106-9

Chamberlain, G. P. (2006). Researching strategy formation process: An abductive methodology. Quality \& Quantity, 40, 289-301. https://doi.org/10.1007/s11135-005-8094-3

Conn, V. S., Zerwic, J., Rawl, S., Wyman, J. F., Larson, J. L., Anderson, C. M., Fahrenwald, N. 1., Benefield, L. E., Cohen, M. Z., Smith, C. E., Topp, R., \& Markis, N. E. (2014). Strategies for a successful Ph.D. program: Words of wisdom from the WJNR editorial board. Western Journal of Nursing Research. 36(1), 6-30. https://doi.org/10.1177/0193945913492144

Cornwall, J., Mayland, E, C., Meer, J, v, d., Spronken-Smith, R, A., Tustin, C., \& Blyth, P. (2018). Stressors in early-stage doctoral students. Studies in Continuing Education, 41(3), 363-380. https://doi.org/10.1080/0158037X.2018.1534821

Davis, A., Wladkowski, S, P., \& Mirick, R, G. (2017). Lessons learned for successful dissertation completion from social work doctoral graduates. Journal of Teaching in Social Work, 37(2), 107-120. http://dx.doi.org/10.1080/08841233.2017.1295124

Devos, C., Linden, N. V. L., Boudrenghien, G., Azziz, A., Frenay, M., Galand, B., \& Klein, O. (2015). Doctoral supervision in the light of the three types of support promoted in selfdetermination theory. International Journal of Doctoral Studies, 10, 439-464. https://doi.org/10.28945/2308

Fernandez, M., Sturts, J., Duffy, L, N., Larson, L, R., Gray, J., \& Powell, G, M. (2019). Surviving and Thriving in Graduate School. SCHOLE: A Journal of Leisure Studies and Recreation Education, 34(1), 3-15. https://doi.org/10.1080/1937156X.2019.1589791

Friedman, D. A. (2012). How to collect and analyze qualitative data. In Mackey, A \& Gass, S, M (Eds), Research methods in second language acquisition: A practical guide (pp. 180-200). West Sussex: Willey-Blackwell. https://doi.org/10.1002/9781444347340.ch10

Hajar, A. (2016). Understanding Arab students' challenges, strategy use, and future vision while writing their Masters dissertations at a UK University: A qualitative inquiry. Innovation in Language Learning and Teaching, 12(3), 260-273. http://dx.doi.org/10.1080/17501229.2016.1199555 
Holmes, B. D., Robinson, L., \& Seay, A. D. (2010). Getting to finished: Strategies to ensure completion of the doctoral dissertation. Contemporary Issues in Education Research, 3(7), 18. https://doi.org/10.19030/cier.v3i7.215

Hu, J., \& Gao, X. A. (2017). Self-regulated strategic writing for academic studies in an Englishmedium-instruction context, Language and Education, 32(1), 1-20. https://doi.org/10.1080/09500782.2017.1373804

Huerta, M., Goodson, P., Beigi, M., \& Chlup, D. (2016). Graduate students as academic writers: Writing anxiety, self-efficacy and emotional intelligence. Higher Education Research \& Development, 36(4), 716-729. http://dx.doi.org/10.1080/07294360.2016.1238881

Jackson \& Park. (2020). Self-regulation and personality among L2 writers: Integrating trait, state, and learner perspectives. Journal of Second Language Writing, 49, 1-17. https://doi.org/10.1016/j.jslw.2020.100731

Jones, M. (2013). Issues in doctoral studies - Forty years of journal discussion: Where have we been and where are we going? International Journal of Doctoral Studies, 8(6), 83-104. https://ro.uow.edu.au/buspapers/175/

Lech, A. M., Nieuwerburgh, C. v., \& Jalloul. S. (2017). Understanding the experience of Ph.D. students who received coaching: an interpretative phenomenological analysis, Coaching: An International Journal of Theory, Research and Practice, 11(1), 1-15. https://doi.org/10.1080/17521882.2017.1381753

Lei, X. (2016). Understanding writing strategy use from a sociocultural perspective: The case of skilled and less-skilled writers. System, 60, 105-116. https://doi.org/10.1016/j.system.2016.06.006

Lukes, L, A., Jones, J. P., \& McConnell, D, A. (2021). Self-regulated learning: Overview and potential future directions in geoscience. Journal of Geoscience Education, 69(1), 14-26. https://doi.org/10.1080/10899995.2020.1820828

Mullen, C. A. (2005). Fire and ice: Igniting and channeling passion in new qualitative researchers. Peter Lang.

Odena, O., \& Burgess, H. (2015). How doctoral students and graduates describe facilitating experiences and strategies for their thesis writing learning process: A qualitative approach. Studies in Higher Education, 42(3), 572-590. http://dx.doi.org/10.1080/03075079.2015.1063598

Paltridge, B. (2004). Thesis and dissertation writing: An examination of published advice and actual practice. English for Specific Purposes. 21(2), 125-143. https://doi.org/10.1016/S08894906(00)00025-9

Rahimi, M., Yousoffi, N., \& Moradkhani, S. (2018). Research practice in higher education: Views of postgraduate students and university professors in English language teaching. Cogent Education, 5(1), 1-23. https://doi.org/10.1080/2331186X.2018.1560859

Ranalli, J. (2018). Automated written corrective feedback: how well can students make use of it?, $\begin{array}{llll}\text { Computer Assisted Language } & \text { Learning. }\end{array}$ https://doi.org/10.1080/09588221.2018.1428994

Rooij, E, v, Fokkens-Bruinsma, M., \& Jansen, E. (2019). Factors that influence Ph.D. candidates' success: The importance of Ph.D. project characteristics. Studies in Continuing Education. 120. https://doi.org/10.1080/0158037X.2019.1652158

Russell-Pinson, L \& Harris, M, L. (2019). Anguish and anxiety, stress and strain: Attending to writers' stress in the dissertation process. Journal of Second Language Writing, 43, 63-71. https://doi.org/10.1016/j.jslw.2017.11.005 
Shahsavar, Z., \& Kourepaz, H. (2020). Postgraduate students' difficulties in writing their theses $\begin{array}{llll}\text { literature review. } & \text { Cogent }\end{array}$ https://doi.org/10.1080/2331186X.2020.1784620

Shin, J. C., Kim, S. J., Kim, E., and Lim, H. (2018). Doctoral students' satisfaction in a researchfocused Korean university: Socio-environmental and motivational factors. Asia Pacific Education Review. 19: 159-168. https://doi.org/10.1007/s12564-018-9528-7

Teng, L. S., \& Zhang, L. (2016). A questionnaire-based validation of multidimensional models of self-regulated learning strategies. The Modern Language Journal, 100(3), 674-701. https://doi.org/10.1111/modl.12339

Teng, M. F. (2019). The role of metacognitive knowledge and regulation in mediating university EFL learners' writing performance. Innovation in Language Learning and Teaching, 14(5), 436-50. https://doi.org/10.1080/17501229.2019.1615493

Umamah, A., \& Cahyono, B. Y. (2020). Indonesian university students' self-regulated writing (SRW) strategies in writing expository essays. Indonesian Journal of Applied Linguistics, 10(1), 25-35. https://doi.org/10.17509/ijal.v10i1.24958

Wang, T., \& Li, L. Y. (2008). Understanding international postgraduate research students' challenges and pedagogical needs in thesis writing. International Journal of Pedagogies and Learning, 4(3), 88-96. http://dx.doi.org/10.5172/ijpl.4.3.88

Widharyanto, B., \& Binawan, H. (2020). Learning style and language learning strategies of students from various ethnics in Indonesia. Cakrawala Pendidikan, 39(2), 480-492. https://doi.org/10.21831/cp.v39i2.28173

Winne, P. H., \& Hadwin, A. F. (1998). Studying as self-regulated learning. In D. J. Hacker, J. Dunlosky, \& A. C. Graesser (Eds.), Metacognition in educational theory and practice (pp. 277-304). Mahwah: Lawrence Erlbaum Associates.

Yang, C., \& Bai, L. (2019). The use of metacognitive strategies by Chinese PhD students of social sciences in Australian universities. International Journal of Educational Research, 93, 43-52. https://doi.org/10.1016/j.ijer.2019.06.007

Yin, R. K. (2013). Validity and generalization in future case study evaluations. Evaluation, 19(3), 321-332. https://doi.org/10.1177/1356389013497081

Yonezawa, A. (2015). Connecting higher education research in Japan with the international academic community. Higher Education Policy, 28, 477-493. https://doi.org/10.1057/hep.2015.19

Zimmerman, B. J. (2000). Attaining self-regulation: A social cognitive perspective. In Boekaerts, M, Pintrich, P, R, \& Zeidner, M. (Eds.), Handbook of self-regulation. (pp. 13-39). San Diego, CA: Academic Press. https://doi.org/10.1016/B978-012109890-2/50031-7

Zimmerman, B. J. (2013). From Cognitive modeling to self-regulation: A social cognitive career path. Educational Psychologist, 48(3), 135-147.

https://doi.org/10.1080/00461520.2013.794676 